ISSN 0103-8478

\title{
Proteínas de fase aguda em cadelas com neoplasia mamária
}

\author{
Acute phase proteins in female dogs with mammary tumors
}

\author{
Michelly Kheidy Borges Battisti ${ }^{I}$ Daniella Matos da Silva ${ }^{I}$ Mhayara Samile de Oliveira Reusing \\ Olair Carlos Beltrame ${ }^{\mathrm{I}}$ Elizabeth Moreira dos Santos Schmidt ${ }^{\mathrm{II}}$ José Jurandir Fagliari $^{\mathrm{II}}$ \\ Rosângela Locatelli Dittrich ${ }^{\mathrm{I}}$ Simone Domit Guérios ${ }^{\mathrm{I}^{*}}$
}

RESUMO

As proteínas de fase aguda (PFA) apresentam concentrações séricas alteradas mediante processos infecciosos, inflamatórios e neoplásicos. Objetivou-se com este trabalho avaliar as variações séricas das PFA em cadelas portadoras de neoplasia mamária, comparando com a avaliação histológica e leucograma. As PFA foram avaliadas em 45 cadelas com tumor de mama, distribuídas nos grupos neoplasia benigna $(n=13)$, maligna não ulcerada $(n=24)$ e maligna ulcerada $(n=8)$. O grupo controle foi composto por 20 cadelas saudáveis. Foram realizados o teste de eletroforese em gel de poliacrilamida contendo dodecil sulfato de sódio (SDS-PAGE) para identificar as PFA (albumina, ceruloplasmina, transferrina, haptoglobina $\mathrm{Hp}, \alpha-1$ antitripsina e $\alpha-1$ glicoproteina ácida) e o teste ultrassensivel para proteina $C$ reativa $(P C R)$. As pacientes com neoplasia mamária maligna ulcerada apresentaram elevações sérica para PCR e Hp e redução da albumina $(P<0,05$, one-way ANOVA e Teste de Dunn). Nessas pacientes, foi observada correlação positiva entre o leucograma inflamatório e o aumento das PFA ( $P=0,002$, Teste de Fisher) e não foram observadas correlações entre as PFA e os subtipos histológicos. Conclui-se que avaliações conjuntas da PCR, Hp e albumina podem ser utilizadas como ferramenta de auxílio diagnóstico e prognóstico em cadelas com neoplasia mamária.

Palavras-chave: câncer, proteína C reativa, haptoglobina, albumina.

\section{ABSTRACT}

Acute phase proteins (APPs) are serum proteins whose concentrations change after infectious and inflammatory disease, and cancer. The aims of this study were to evaluate changes in APPs concentration and to correlate these findings with histological classification and WBC in female dogs with mammary tumors. APPs were studied in 45 female dogs with mammary tumor distributed in the following groups: benign $(n=13)$, malignant without tumor ulceration $(n=24)$, and malignant with tumor ulceration $(n=8)$. SDS-polyacrylamide gel (SDS-PAGE) electrophoresis was used to measure APPs concentrations (albumin, ceruloplasmin, transferrin, haptoglobinHp, $\alpha$-1-acid glycoprotein and $\alpha$-1-antitrypsin) and ultrasensitive assay was used to evaluate serum C-reactive protein (CRP). Patients with malignant mammary neoplasia plus ulceration had significant increase of CRP and Hp, and had decreased levels of albumin $(P<0.05$, one-Way ANOVA and Dunn Test). Positive correlation among APPs and inflammatory leukocytosis were observed $(P=0.002$, Fisher test $)$. No correlation was observed between APPs and histological subtype. In conclusion, combined changes of CRP, Hp and albumin may be used as a prediagnostic tool and prognosis in dogs with mammary tumors.

Key words: cancer, $C$-reactive protein, haptoglobin, albumin.

\section{INTRODUÇÃO}

Os tumores mamários são as neoplasias mais frequentes em cadelas com idade superior a cinco anos que não foram submetidas à castração antes do primeiro cio. Aproximadamente 50 a $70 \%$ das neoplasias mamárias apresentam classificação histológica maligna, contudo, a evolução clínica e a ocorrência de metástase regional e/ou distante

'Departamento de Medicina Veterinária, Universidade Federal do Paraná (UFPR), 80035-050, Curitiba, PR, Brasil. E-mail: sdguerios@ufpr.br. *Autor para correspondência.

"Faculdade de Medicina Veterinária e Zootecnia de Botucatu (FMVZ), Universidade Estadual Paulista Júlio de Mesquita Filho (UNESP), Botucatu, SP, Brasil.

"IIDepartamento de Clínica e Cirurgia Veterinária, Faculdade de Ciências Agrárias e Veterinárias de Jaboticabal (FCAV), UNESP, Jaboticabal, SP, Brasil. 
podem variar drasticamente entre os indivíduos (FONSECA \& DALECK, 2000; ZUCCARI et al., 2001). Marcadores tumorais vêm sendo utilizados para auxiliar no diagnóstico precoce e no prognóstico de diferentes neoplasias. Muitos desses marcadores são substâncias detectadas e quantificadas no sangue, fluidos e/ou tecidos corporais, dentre os quais se destacam as proteínas de fase aguda (PFA).

As PFA são classificadas em positivas e negativas, sendo positivas aquelas cuja concentração sérica eleva-se nos processos infecciosos, inflamatórios ou neoplásicos e, por sua vez, as negativas são aquelas na qual a concentração sérica reduz em resposta a algum desses processos. As PFA positivas são subdividas em PFA positivas maiores (quando a concentração sérica se eleva rapidamente, retornando aos valores basais também de forma rápida) e PFA positivas moderadas (quando a concentração sérica aumenta lentamente e permanece elevada por mais tempo). No cão, as principais PFA positivas maiores são a proteína $\mathrm{C}$ reativa $(\mathrm{PCR})$ e $\mathrm{o}$ amiloide sérico A (ASA), e a principal PFA positiva moderada é representada pela Haptoglobina (Hp). As principais PFA negativas são a albumina e a transferrina (CERÓN et al., 2005).

As PFA participam da resposta inflamatória inicial e são mediadas por citocinas pró-inflamatórias como a interleucina-1 (IL-1), fator de necrose tumoral $\alpha(\mathrm{FNT} \alpha)$ e interleucina-6 (IL-6). Possuem diversas funções que incluem o auxílio da homeostase corporal pelo controle da infecção e inflamação que se estabelece logo após o dano celular, inibição da quimiotaxia e modulação dos neutrófilos, indução de citocinas e formação de anticorpos (MURATA et al., 2004; CÉRON, et al., 2005; THEILGAARDMÖNCH, et al., 2006).

As PFA também sofrem alterações frente a processos neoplásicos (CÉRON, et al., 2005; CALAZANS et al., 2009; MYLONAKIS et al., 2011). Estudos recentes demonstraram variações nas PFA em cães portadores de tumores mamários, pancreáticos, carcinoma de células escamosas e linfoma (CALAZANS et al., 2009;GALEZOWSKI et al., 2010; MUKORERA et al., 2011), e em seres humanos no câncer de próstata e mama (STARK et al., 2009). Nas neoplasias mamárias, as variações dos valores séricos das PFA podem ocorrer em função da inflamação tecidual crônica, do tamanho do tumor primário e da presença de metástases (TECLES et al., 2009; CROSSLEY et al., 2010). Não há consenso em relação às alterações séricas das PFA em cadelas com neoplasia mamária e o perfil analítico dessas, associadas à classificação histopatológica e ao leucograma dos pacientes, é desconhecido. Objetivou-se com este trabalho avaliar as alterações nas concentrações séricas das principais PFA positivas (PCR, Hp, ceruloplasmina, alfa-1antitripsina, alfa-1-glicoproteína ácida) e negativas (albumina e transferrina) e comparar os achados ao leucograma e à análise histopatológica, em cadelas com neoplasia mamária.

\section{MATERIAL E MÉTODOS}

Foram selecionadas 45 cadelas de idades e raças variadas, diagnosticadas comneoplasia mamária, atendidas no Hospital Veterinário da Universidade Federal do Paraná - Curitiba (HV-UFPR), no período entre março e dezembro de 2011. Foram excluídas do estudo cadelas com doenças concomitantes à neoplasia e/ou submetidas a tratamento oral, injetável ou tópico (anti-inflamatórios, antiparasitários, antibióticos e antifúngicos) ou vacinadas em período inferior a quatro meses da data da consulta.

O sangue colhido das pacientes durante o diagnóstico clínico foi armazenado em tubos de ensaio com anticoagulante ácido etilenodiaminotetracético (EDTA) para realização do leucograma e sem anticoagulante para realização do proteinograma sérico e análise da PCR. Após centrifugação a 2500 rotações por minuto, durante 5 minutos, o soro obtido foi armazenado em freezer comum a $-20^{\circ} \mathrm{C}$ até a realização do proteinograma.

A determinação da concentração da proteína sérica total (PST) foi realizada pelo método de Biureto (Labtest ${ }^{\circledR}$, Belo Horizonte) com leitura em espectrofotômetro semi-automatizado (Labquest $^{\circledR}$, São Paulo). A determinação das concentrações das frações proteicas foi realizada por eletroforese em matriz gel de poliacrilamida, contendo dodecil sulfato de sódio (SDS-PAGE), utilizando o sistema vertical para eletroforese (LAEMMLI, 1970). A placa gel foi colocada em cuba com solução tampão de $\mathrm{pH}$ 8,5. As amostras para fracionamento das proteínas foram preparadas com $10 \mu \mathrm{L}$ de soro sanguíneo diluído em $30 \mu \mathrm{L}$ de tampão fosfato (PBS) e $20 \mu \mathrm{L}$ de gel, e aquecidas sobre água em ebulição por 10 minutos. As alíquotas de $5 \mu \mathrm{L}$ foram depositadas nos fossos da placa gel para receber estímulo elétrico e iniciar a corrida. Terminada a separação, o gel foi corado com Coomassie blue 0,2\% e depois descorado até que as bandas de proteínas estivessem nítidas. Os pesos moleculares e as concentrações das proteínas foram obtidos por densitometria computadorizada (SHIMADZU CS-9301, Kyoto, Japão), através do escaneamento das amostras. O resultado final 
foi demonstrado em gráficos com curvas que representaram as frações das proteínas e dados de percentual e peso molecular de cada proteína obtida na análise.

A concentração sérica da PCR foi obtida pelo teste turbidimétrico ultrassensível com látex aprimorado (Biotécnica ${ }^{\circledR}$ Varginha, Minas Gerais). $\mathrm{O}$ método consiste na aglutinação de partículas de látex recobertas com anticorpo que aglutinam quando entram em contato com a PCR presente na amostra, causando mudança de absorbância, proporcional à concentração da PCR existente. A alteração na absorbância foi quantificada em analisador de química clínica automatizado (BS200 Mindray ${ }^{\circledR}$, China). A calibração do equipamento foi realizada com calibrador para PCR (Biotécnica ${ }^{\circledR}$ Varginha, Minas Gerais), com cinco pontos de diferentes concentrações de 0 a $8 \mathrm{mgL}^{-1}$ em 546nm, de acordo com a programação do equipamento (BS200 Mindray ${ }^{\circledR}$, China; $300 \mu \mathrm{L}$ de reagente e $3 \mu \mathrm{L}$ de amostra). Após a calibração do equipamento, antes da realização dos testes da PCR no soro dos pacientes, foi dosada a PCR em soro controle (Biotécnica ${ }^{\circledR}$ Varginha, Minas Gerais) para avaliar a precisão das determinações, e o resultado obtido encontrou-se dentro da faixa de referência indicada na bula do controle.

A contagem de leucócitos foi realizada em hemocitômetro e os esfregaços sanguíneos foram utilizados para a contagem de diferencial.A presença de inflamação foi avaliada pelo leucograma (leucocitose, neutrofilia, monocitose, desvio nuclear à esquerda).

As pacientes com neoplasia mamária foram submetidas à mastectomia e o tecido mamário encaminhado para análise histopatológica e classificação, segundo critérios da Organização Mundial da Saúde (MEUTEN, 2002). Após a avaliação histopatológica, as pacientes foram divididas em três grupos: portadoras de neoplasia benigna, neoplasia maligna não ulcerada e maligna ulcerada.

Para o grupo controle, foram selecionadas 20 cadelas clinicamente saudáveis com idade média de cinco anos (3 a 8 anos), encaminhadas ao HVUFPR para ovariohisterectomia eletiva ou vacinação. Foram realizados exames clínicos, hematológicos e de imagem (ultrassonografia abdominal e radiografia torácica), a fim de atestar higidez das pacientes.

$\mathrm{O}$ teste de Kolmogorov-Smirnov foi empregado para verificar a normalidade dos resultados. As concentrações séricas das PFA obtidas por eletroforese resultaram em dados não paramétricos, que foram avaliadas pelo teste de análise de variância de Kruskal-Wallis e o teste Dunn para a comparação dos grupos. A PCR e a idade das pacientes resultaram em dados paramétricos, sendo empregado o teste de análise de variância one-way ANOVA, seguido do teste de Tukey para comparação entre os grupos. $\mathrm{O}$ teste exato de Fisher foi aplicado para verificar a correlação entre as PFA e a presença de inflamação. Valores de $\mathrm{P}<0,05$ foram considerados significativos.

\section{RESULTADOS}

As pacientes portadoras de neoplasia apresentaram média de idade semelhante entre os grupos $(\mathrm{P}>0,05)$. A média de idade para o grupo de pacientes com neoplasia benigna foi de 8,8 anos ( 3 a 16 anos), para as pacientes com neoplasia maligna não ulcerada 9,8 anos ( 5 a 15 anos) e as com neoplasia maligna ulcerada 9,1 anos (5 a14 anos).

De acordo com o resultado da avaliação histopatológica, $71,1 \% \quad(32 / 45)$ das cadelas apresentaram tumores mamários malignos e 28,9\% (13/45) benignos. Nenhuma paciente com neoplasia mamária benigna apresentou ulceração tumoral e, no grupo de neoplasias mamárias malignas, 25\%(8/32) estavam ulceradas e 75\%(24/32) não apresentaram ulceração tumoral.

No grupo com neoplasia benigna $53,8 \%$ (7/13), foram classificadas como adenoma simples, $23,1 \%$ (3/13) adenoma complexo e 23,1\% (3/13) tumor misto benigno. No grupo com neoplasia maligna, 59,4\% (19/32) foram classificadas como carcinoma simples, 15,6\% (5/32) carcinoma papilífero cístico, $12,5 \%$ (4/32) carcinoma papilífero simples a complexo, 9,4\% (3/32) carcinoma complexo e $3,1 \%$ (1/32) carcinoma sólido.

A eletroforese evidenciou seis PFA: ceruloplasmina, transferrina, albumina, alfa-1antitripsina, haptoglobina $(\mathrm{Hp})$ e alfa-1-glicoproteína ácida. O resultado do proteinograma sérico dos grupos controle, neoplasia benigna, neoplasia maligna não ulcerada e neoplasia maligna ulcerada estão na tabela 1 .

A única alteração proteica observada nas pacientes com neoplasia benigna $(n=13)$ foi a elevação da $\mathrm{Hp}\left(21,94 \pm 6,65 \mathrm{mgL}^{-1} ; \mathrm{P}=0,0016\right.$, Teste de Dunn), quando comparado ao controle $\left(12,52 \pm 4,64 \mathrm{mgL}^{-1}\right)$. A média da PCR para o grupo neoplasia benigna $\left(0,49 \pm 0,45 \mathrm{mgdL}^{-1} ; \mathrm{P}=0,09\right.$, OneWay ANOVA, post hoc Tukey) foi semelhante ao grupo controle $\left(0,35 \pm 0,41 \mathrm{mgL}^{-1}\right)$. O leucograma não apresentou alterações nas pacientes portadoras de tumores benignos.

$\mathrm{O}$ valor sérico médio da $\mathrm{Hp}$ elevou-se nas pacientes com neoplasia de mama maligna não 
Tabela 1-Valores séricos da proteína total, proteína C reativa (PCR) e das demais proteínas de fase aguda (PFA) em cadelas com neoplasia mamária e controle.

\begin{tabular}{|c|c|c|c|c|}
\hline $\begin{array}{l}\text { Proteínas } \\
\text { (Peso molecular kDa) }\end{array}$ & $\begin{array}{l}\text { Controle } \\
(\mathrm{n}-20)\end{array}$ & $\begin{array}{l}\text { Neoplasia benigna } \\
\qquad(\mathrm{n}-13)\end{array}$ & $\begin{array}{l}\text { Neoplasia maligna não ulcerada } \\
\qquad\left(\mathrm{n}^{-}=24\right)\end{array}$ & $\begin{array}{l}\text { Neoplasia maligna ulcerada } \\
\qquad(\mathrm{n}-8)\end{array}$ \\
\hline Proteina total $\left(\mathrm{gdL}^{-1}\right)$ & $6,8+0,4$ & $6,4 \pm 1,1$ & $7,1 \pm 1,6$ & $6,3+0,9$ \\
\hline $\operatorname{PCR}(25)$ & $0,35 \pm 0,4^{\mathrm{a}}$ & $0,49 \pm 0,4^{\mathrm{a}}$ & $0,53+0,7^{b}$ & $2,32+1,6^{b, c}$ \\
\hline Ceruloplasmina(125) & $29 \pm 8,1$ & $27,9 \pm 11,9$ & $26,7 \pm 10,7$ & $39,1 \pm 10,3$ \\
\hline Transferrina(85) & $77,2 \pm 48,4$ & $74,6 \pm 89,4$ & $54,7 \pm 36,9$ & $80,5 \pm 24,1$ \\
\hline Albumina $(65)$ & $3713^{\mathrm{a}}+689,3$ & $3640^{\mathrm{a}}+740,3$ & $3555^{\mathrm{a}}+1230$ & $2959^{\mathrm{b}}+305,1$ \\
\hline Alfa1-antitripsina (60) & $350 \pm 56$ & $297,4+75,2$ & $348+25,5$ & $307,6 \pm 95,9$ \\
\hline Haptoglobina(39) & $12,5^{\mathrm{a}}+4,6$ & $21,9^{\mathrm{b}}+6,6$ & $22,8^{b}+10,7$ & $34,7^{\mathrm{b}}+21,3$ \\
\hline Alfa1-glicoproteína ácida (37) & $11,2 \pm 6,1$ & $19,6+8,1$ & $22,9+24,9$ & $22,9+18$ \\
\hline
\end{tabular}

Os valores são apresentados como média-desvio padrão. Médias seguidas por letras diferentes na mesma linha diferem entre si, One-way ANOVA post hocTukey para a PCR e teste múltiplo de comparação de Dunn para as outras proteínas (P<0,05). *Valor zero atribuído à proteína não mensurada em uma amostra.

ulcerada $\left(22,81 \pm 10,79 \mathrm{mgL}^{-1} ; \mathrm{P}=0,0003\right.$, Teste de Dunn) e ulcerada $\left(34,71 \pm 21,34 \mathrm{mgL}^{-1} ; \mathrm{P}=0,0002\right.$, Teste de Dunn), quando comparados ao grupo controle $\left(12,52 \pm 4,64 \mathrm{mg} \mathrm{L}^{-1}\right)$. A PCR apresentou concentração sérica elevada nos grupos neoplasia mamária não ulcerada $\left(0,53 \pm 0,71 \mathrm{mgL}^{-1} ; \mathrm{P}=0,0097\right.$, One-Way ANOVA, post hoc Tukey) e neoplasia mamária ulcerada $\left(2,32 \pm 1,63 \mathrm{mgL}^{-1} ; \mathrm{P}=0,0012\right.$, OneWay ANOVA, post hoc Tukey), quando comparados ao grupo controle $\left(0,35 \pm 0,41 \mathrm{mgL}^{-1}\right)$ e entre os grupos malignos $(\mathrm{P}=0,002$, One-Way ANOVA, post hoc Tukey). A albumina teve a média diminuída apenas para o grupo neoplasia maligna ulcerada (2959 $\pm 305,1 \mathrm{mgdL}^{-1} ; \mathrm{P}=0,007$, Teste de Dunn), quando comparada ao grupo controle $\left(3713 \pm 689,3 \mathrm{mgdL}^{-1}\right)$.

O leucograma revelou inflamação em 50\% das pacientes com neoplasia mamária maligna não ulcerada (12/24) e 87,5\% (7/8) das ulceradas. O grupo neoplasia mamária maligna ulcerada apresentou correlação positiva entre as alterações nas PFA (PCR, Hp e albumina) e a presença de leucograma inflamatório $(\mathrm{P}=0,002$, Teste de Fisher). Não foi observada correlação entre as alterações nas PFA (PCR, Hp e albumina) e a presença de leucograma inflamatório para os grupos neoplasia benigna e maligna não ulcerada ( $\mathrm{P}>0,05$, Teste de Fisher).

\section{DISCUSSÃO}

O presente trabalho revelou que a PCR e a Hp estão positivamente associadas à neoplasia mamária, estando ou não relacionadas ao leucograma inflamatório. No entanto, conforme verificado neste estudo, a avaliação em conjunto de uma PFA positiva maior como a PCR, com uma moderada (Hp), apresenta vantagens quanto à avaliação individual dessas proteínas (TECLES et al., 2009). Desse modo, este estudo observou aumento na PCR e na Hp em todas as pacientes com neoplasia mamária maligna, ulcerada ou não. As pacientes com neoplasia mamária benigna apresentaram aumento apenas da Hp e não da PCR, confirmando que a neoplasia mamária maligna é uma doença que promove inflamação crônica, maior lesão tecidual e necrose tumoral, quando comparada à neoplasia mamária benigna (PLANELLAS et al., 2009; TECLES et al., 2009).

A presença de ulceração é característica de um estadio mais avançado da neoplasia mamária e, nessas pacientes, a inflamação tecidual da massa tumoral é evidente. No presente estudo, o leucograma inflamatório associado ao aumento expressivo da PCR e da Hp e redução na albumina foram observados nas pacientes com neoplasia ulcerada. Esse resultado indica que o aumento das PFA em cadelas com neoplasia mamária maligna ulcerada ocorre pela maior inflamação tecidual (CÉRON et al., 2005; GRIEBSCH et al., 2009; GALEZOWSKI,et al., 2010). A inflamação peritumoral leva à ativação de macrófagos e à liberação de citocinas, que são importantes na ativação da resposta de fase aguda, com consequentes alterações das PFA (BALKWILLet al., 2005; ROXBURGH \& McMILLAN, 2010). Outro fator a ser considerado é a maior expressão de ciclooxigenase 2(COX2) no carcinoma mamário, o que leva à maior liberação das PFA através da estimulação desses receptores (HELLER et al., 2005; PLANELLAS et al., 2009). A avaliação individual do leucograma das pacientes com neoplasia mamária não revelou um padrão no perfil inflamatório, apesar do aumento da PCR e da Hp sérica, revelando que as 
PFA podem estar aumentadas, mesmo em pacientes sem alterações no hemograma.

Alteração individual de PFA em cães com neoplasia foi demonstrada em pesquisas recentes, apesar do não estabelecimento de um padrão dessas alterações (PLANELLAS et al., 2009; TECLES et al., 2009; CROSSLEY et al., 2010; GALEZOWSKI et al., 2010; MUKORERA et al., 2011). O aumento da PCR foi demonstrado em cães com neoplasia mamária e correlacionado com pior prognóstico (CROSSLEY et al., 2010; MUKORERA et al., 2011). Contraditoriamente, a avaliação sérica em conjunto da Hp e da PCR não apresentou valor diagnóstico ou prognóstico em cadelas com tumor de mama (PLANELLAS et al., 2009), apesar de observações na elevação da Hp em seres humanos com câncer de ovário (YE et al., 2003), pâncreas (OKUYAMA et al., 2006) e adenocarcinoma uterino (NABLI et al., 2009).

A albumina é uma proteína de fase aguda negativa e a redução observada apenas nas pacientes com neoplasia maligna ulcerada pode ser devido ao aumento expressivo da PCR e da Hp neste grupo, obedecendo um mecanismo de compensação. As citocinas pró-inflamatórias diminuem a síntese da albumina, uma vez que promovem a síntese de outras PFA (CALAZANS et al., 2009).

\section{CONCLUSÃO}

A PCR e a Hp são proteínas inespecíficas, porém, altamente sensíveis, podendo ser usadas como ferramentas auxiliares no diagnóstico e prognóstico de neoplasia mamária em cadelas. A avaliação combinada da PCR e Hp é mais vantajosa que a individual e pode sugerir malignidade, não havendo aparente relação com o tipo histológico ou leucograma inflamatório, que está mais associado ao padrão ulcerativo do tumor.

\section{AGRADECIMENTOS}

Os autores agradecem à BioTécnica, pela doação do teste ultrassensível para PCR, e à Fundação Araucária pelo financiamento da bolsa de Mestrado de Michelly Battisti.

\section{COMITÊ DE ÉTICA E BIOSSEGURANÇA}

O presente trabalho foi aprovado pelo comitê de ética no uso de animais (CEUA), sob protocolo n.058/2011.

\section{REFERÊNCIAS}

BALKWILL, F.et al. Smoldering and polarized inflammation in the initiation and promotion of malignant disease. Cancer Cell, v.7, p.211-217, 2005. Disponível em: <http://dx.doi.org/10.1016/j. ccr.2005.02.013>. Acesso em: 22 ago. 2012. doi: 10.1016/j. ccr.2005.02.013.

CALAZANS, S.G.et al. Proteinograma sérico de cães sadios e com linfoma obtido por eletroforese em gel de poliacrilamida (SDS-PAGE). Arquivo Brasileiro de Medicina Veterinária e Zootecnia, v.61, n.5, p.1044-1048, 2009. Disponível em: <http:// dx.doi.org/10.1590/S0102-09352009000500005>. Acesso em: 22 ago. 2012. doi:10.1590/S0102-09352009000500005.

CERÓN J.J.et al. Acute phase proteins in dogs and cats: current knowledge and future perspectives. Veterinary Clinical Pathology, v.34, p.85-99, 2005. Disponível em: <http://dx.doi. org/10.1111/j.1939-165X.2005.tb00019.x>. Acesso em: 22 ago. 2012. doi:10.1111/j.1939-165X.2005.tb00019.x.

CROSSLEY, R.et al. Determinación de proteína C-reactiva em hembras caninas con tumores mamarios benignos $y$ malignos. Archivos de Medicina Veterinaria, v.42, p.101105, 2010. Disponível em: <http://dx.doi.org/10.4067/S0301732X2010000100014>. Acesso em: 22 ago. 2012. doi:10.4067/ S0301-732X2010000100014.

FONSECA, C.S; DALECK, C.R. Neoplasias mamárias em cadelas: influência hormonal e efeitos da ovário-histerectomia como terapia adjuvante. Ciência Rural, v.30, n.4, p.731735, 2000. Disponível em: <http://dx.doi.org/10.1590/S010384782000000400030>. Acesso em: 22 ago. 2012. doi:10.1590/ S0103-84782000000400030.

GALEZOWSKI, A.M.et al. C-Reactive Protein as a prognostic indicator in dogs with acute abdomen syndrome. Journal of Veterinary Diagnostic Investigation, v.22, p.395-401, 2010. Disponível em: <http://dx.doi.org/10.1177/104063871002200308>. Acesso em: 22 ago. 2012. doi:10.1177/104063871002200308.

GRIEBSCH,C.et al. C-reactive protein concentration in dogs with primary immunomediate hemolytic anemia. Veteterinary Clinical Pathology, v.38, p.421-425, 2009. Disponível em: <http://dx.doi. org/10.1111/j.1939-165X.2009.00146.x>. Acesso em: 22 ago. 2012. doi:10.1111/j.1939-165X.2009.00146.x.

HELLER, D.A, et al. Cyclooxygenase-2 expression is associated with histologic tumor type in canine mammary carcinoma. Veterinary Pathology, v.42, p.776-780, 2005.Disponível em: <http://dx.doi.org/10.1354/vp.42-6-776>. Acesso em: 22 ago. 2012. doi:10.1354/vp.42-6-776.

LAEMMLI, U.K. Cleavage of structural proteins during the assembly of the head of bacteriophage T4. Nature, v.227, n.5259, p.680-685, 1970. Disponível em: <http://bioinfepcri.org/misc/ nature.pdf $>$. Acesso em: 9 nov. 2012.

MEUTEN, D.J. Tumors in domestic animals. Iowa:WileyBlackwell, 2002. 800p.

MUKORERA, V.et al. Serum C-reactive protein concentration in benign and malignant canine spirocercosis. Journal of Veterinary Internal Medicine, v.25, p.963-966, 2011. Disponível em: <http:// dx.doi.org/10.1111/j.1939-1676.2011.0733.x >. Acesso em: 22 ago. 2012. doi:10.1111/j.1939-1676.2011.0733.x.

MURATA, H.et al. Current research on acute phase proteins in veterinary diagnosis: an overview. Veterinary Journal, v.168, p.28-40, 2004. Disponível em: <http://dx.doi.org/10.1016/S10900233(03)00119-9>. Acesso em: 22 ago. 2012. doi:10.1016/S10900233(03)00119-9. 
MYLONAKIS, M.E.et al. Serum acute phase proteins as clinical phase indicators and outcome predictors in naturally occurring canine monocyticErlichiosis. Journal of Veterinary Internal Medicine, v.25, p.811-817, 2011. Disponível em: <http://dx.doi. org/10.1111/j.1939-1676.2011.0728.x>. Acesso em: 22 ago. 2012. doi:10.1111/j.1939-1676.2011.0728.x.

NABLI, H.et al; Haptoglobin expression in endometrial adenocarcinoma of the uterus. Reproductive Sciences, v.17, n.1, p.47-55, 2010. Disponível em: <http://dx.doi. org/10.1177/1933719109346331>. Acesso em: 22 ago. 2012. doi:10.1177/1933719109346331.

OKUYAMA, N.et al. Fucosylated haptoglobin is a novel marker for pancreatic cancer: A detailed analysis of the oligosaccharide structure and a possible mechanism for fucosylation. International Journal of Cancer, v.118, n.11, p.2803-2808, 2006. Disponível em: 〈http://dx.doi.org/10.1002/ijc.21728>. Acesso em: 22 ago. 2012.doi:10.1002/ijc. 21728 .

PLANELLAS, M. et al. Evaluation of serum haptoglobin and C-reactive protein in dogs with mammary tumors. Veterinary Clinical Pathology, v.38, p.348-352, 2009. Disponível em: <http://dx.doi.org/10.1111/j.1939-165X.2009.00139.x>. Acesso em: 22 ago. 2012.doi:10.1111/j.1939-165X.2009.00139.x.

ROXBURGH, C.S.; McMILLAN, D.C. Role of systemic inflammatory response in predicting survival in patients with primary operable cancer. Future Medicine,v.6, p.149-163, 2010. Disponível em: <http://dx.doi.org/10.2217/fon.09.136>.Acesso em: 22 ago. 2012. doi:10.2217/fon.09.136.
STARK, J.R.et al. Circulatinprediagnostic interleukin-6 and C-reactive protein and prostate cancer incidence and mortality. International Journal of Cancer, v.124, p.2683-2689, 2009. Disponível em: <http://dx.doi.org/10.1002/ijc.24241>. Acesso em: 22 ago. 2012. doi: $10.1002 / \mathrm{ijc} .24241$.

TECLES, F.et al. Serum acute phase protein in female dogs with mammary tumors. Journal of Veterinary Diagnostic Investigation, v.21, p.214-219, 2009. Disponível em: <http:// dx.doi.org/10.1177/104063870902100206>. Acesso em: 22 ago. 2012. doi: $10.1177 / 104063870902100206$.

TEILGAARD-MÖNCH, K. et al. Haptoglobin is synthesized during granulocyte differentiation, stored in specific granules, and realized by neutrophils in response to activation. Blood, v.108, p.353-361, 2006. Disponível em: <http://dx.doi.org/10.1182/ blood-2005-09-3890>. Acesso em: 22 ago. 2012. doi:10.1182/ blood-2005-09-3890.

YE, B.et al. Haptoglobin- $\alpha$ subunit as potential serum biomarker in ovarian cancer identification and characterization using proteomic profiling and mass spectrometry. Clinical Cancer Research, v.9, p.2904-2911, 2003. Disponível em:<http://clincancerres. aacrjournals.org/content/9/8/2904.full.pdf + html? sid=92c144c6ca53-4cb2-836c-b50043469c43>. Acesso em: 22 ago. 2012.

ZUCCARI, D.A.P.C. et al. Correlação entre a citologia aspirativa por agulha fina e a histologia no diagnóstico de tumores mamários de cadelas. Brazilian Journal of Veterinary Researchand Animal Science, v.38, n.1, p.38-41, 2001. Disponível em: <http:// dx.doi.org/10.1590/S1413-95962001000100007>. Acesso em: 22 ago. 2012. doi:10.1590/S1413-95962001000100007. 